\title{
EXPLORING THE LEADERSHIP SKILL AND CHALLENGE IN RESPONDING NATURAL DISASTER: LESSON LEARNING FROM LEADERS INVOLVED IN EMERGENCY RESPONSE OF BANGLADESH
}

\author{
Khalid Md., Bahauddin ${ }^{1}$ and Nayma, Iftakhar ${ }^{2}$ \\ ${ }^{1}$ Integrated Research on Disaster Risk (IRDR), China \\ ${ }^{2}$ KDI School of Public Policy and Management, South Korea
}

\begin{abstract}
Bangladesh is widely known as a land of natural disasters and remains classified as one the most vulnerable countries in the world. Over the last thirty years, Bangladesh has experienced nearly 200 natural disasters accounted for damage of asset, property and, livelihoods and over thousands of death toll. In this connection, effective leadership is critical in order to make disaster response system operative in an effective and efficient manner. This study explores the disaster leadership with a view of identifying the essential leadership skills that are needed by leaders to effectively respond in the aftermath of disaster. It also intends to explore challenges that these leaders face, with a view of improving disaster response leadership. This study revealed that some key essential leadership skills such as intuitiveness, decisiveness, communication, networking, accountability, and learning are required to respond disasters effectively. Findings from this study provided not only an overview of leadership skills needed to face challenges, but also the challenges that these leaders face, with a view of equating the challenges with appropriate skill needed to respond in the context of Bangladesh.
\end{abstract}

Keywords: Disaster, Response, Leadership Skill, Experience, Challenges

\section{INTRODUCTION}

Bangladesh has ranked 5th among the top countries at risk of disaster, according to UN affiliated World Risk Report 2016. The index assessed the risk of disaster in 171 countries through the combined analysis of natural hazards and societal vulnerabilities (Akter, S., Mallick, B., 2016). Bangladesh is extremely vulnerable to natural disaster because of its unique geographic location, high population density and widespread poverty. According to World Bank, in the past two decades, $60 \%$ of the global deaths caused by cyclones were in Bangladesh (Tasneem, S. \& Shindaini, A.J.M., 2013). Over the last four decades, it has been experienced by seven of the ten 20th century's deadliest cyclones. In addition to cyclone, the country is frequently and harshly affected by a large number of natural disasters such as floods, tidal surges, tornadoes, landslides and river erosion (Karim, A., \& Noy, I., 2015). Bangladesh experienced over 200 natural disasters since 1980, leaving a total death toll of approximately 200,000 people and causing economic loss worth nearly $\$ 17$ billion. Every year, Bangladesh incurred 1.8 percent of GDP loss due to natural disasters. It is estimated that 14 percent of Bangladesh's GDP is exposed to disasters (Asgary, A., and Halim, A., 2011). In order to make disaster response system operative in an effective and efficient manner, effective leadership is very essential. The importance of leadership in emergency management is widely acknowledged (Hannah, S. T. et al, 2009). While responding emergencies, leaders are judged from their actions and in actions. Leaders are expected to take charge of the situation, mitigate the effects of the disaster, while being decisive in the midst of anxiety, confusion and chaos. Leaders are expected to be vision oriented, guide the public to safety, while reducing the risks, and navigate through to the murky fields, to that of normalcy (Anderson, D., 2002). So far study on leadership skills in disaster response stage, has not been explored in detail in the context of Bangladesh. So this study is important by exploring the skills of leaders required in responding disasters and documents the experience and challenges the leaders that they faced during disaster response in Bangladesh.

\section{METHODOLOGY OF THE STUDY:}

This work is qualitative in nature and 40 persons (male- 20 and female- 20) who are working in the disaster management sectors in different NGOs and Governmental organization have been selected purposively to know and explore leadership skill, experience, perception and challenges about disaster response activities in Bangladesh. Noted that these 50 studied people participated in different natural disaster response activities such as Cyclone Sidr, 2007; Cyclone Aila, 2009 and Cyclone Roanu, 2016 where they played vital leadership role. They were selected by their organizations to participate in these emergency response activities. Data of this study were collected through group discussions (5), key informant interviews (5) and in-depth Individual interviews (40).

\section{DISASTER AND LEADERSHIP:}

Leadership is a highly contested term, meaning different things to different people. Hailey (2006) defines leadership as '... a process whereby an individual influences a group or31 
individuals to achieve a common goal'. Kouzes and Posner (1995) describe leadership as '... the art of mobilising others to want to struggle for shared aspirations'. Thus, leadership could be viewed as a process of social influence in which one person can enlist the aid and support of others in the accomplishment of a common task. Whilst these two definitions are not necessarily representative of the numerous and sometimes competing notions of leadership, they point out at least three perspectives on leadership. Firstly, some perspectives focus on the traits of successful leaders such as style and approach (Stogdill 1950), for example, charisma to deal with, amongst others, contingencies and challenging situations (Fielder 1967). Secondly, some focus on transformational leaders with the ability to inspire followers during both normal and troubled times, mainly characterised by four Is: idealised influence (more commonly termed charisma), inspirational motivation, intellectual stimulation and individualised consideration (Bass 1985; De Bussy \& Paterson 2012; Yunus \& Anuar 2012). Thirdly, some go beyond perspectives on the traits of leaders and transformational leadership, which essentially focus on the person of the leader. Horner (1997) views leadership as a process in which a leader is not seen as an individual in charge of followers. Rather, a leader is seen as member of a community of practice where people are united in a common enterprise and share a history, values, beliefs, ways of talking and ways of doing things (Drath \& Palus 1994). The leader in these circumstances is akin to what Zolli and Healy (2012) call the 'translational leader' who is not rooted solely in their formal status but in their informal authority and cultural standing. Thus, the leadership imperative is centred on influence, facilitation, collective empowerment, networking and coordination, not command and control (Zolli \& Healy 2012).

The leadership style in disaster management focused on command and control has a long history that is rooted in the military model of emergency preparedness and response. According to Dynes (1994), the assumption of the commandand-control model should be understood in terms of the three Cs. The first ' $C$ ' assumes that disasters are characterised by 'chaos', and the other two 'Cs' suggest that the chaos can be eliminated by command and control. The command-andcontrol formulation, including its mutations such as Incident Management Systems (Perry 2003) and Unified Command Incident Systems (Buck, Trainor \& Aguirre 2006), heavily draws from World War II and the Cold-War era. It recognises the capacity of military organisations to deal with disasters, a view which has been deeply embedded in disaster-management and civil-protection organisations (Dynes 1994). However, Carvalho (2015) states that the wide-ranging systemic breakdowns, interdependencies and the uneven effects of catastrophes indicate that current practices of command-andcontrol leadership are insufficient to the challenges of 'hypercomplex' events. Instead, Carvalho (2015) makes the following claim:

... Transformative leadership that encourages a sense of empowerment, ownership and engagement within the community is required, incorporating a relational approach that constitutes a nexus between leader and follower, with both sides exercising agency. (p. 82)

In the current study, leadership is viewed as a relational and distributed activity. This view of leadership is consistent with the governance approach to DRR. We posit that leadership is one of the essential elements of DRR governance at global, regional, national and local level. The DRR 'platforms' require leadership in order for the stakeholders, comprising United Nations (UN) agencies, government ministries, departments, civil-society groups, donors, International Non-Governmental Organisations (INGOs) and community organisations to share DRR ideas, experiences, expertise, case material and views.

Analysing DRR leadership can be problematic as it requires a framework which captures relational, transformational, translational and distributed leadership, which may also assimilate relevantly to DRR governance. Kirk and Shutte's (2004) framework is adapted to analyse DRR leadership as it captures the basic components of relational, transformational, translational and distributed leadership. The framework has three components of community leadership, which are dialogue, connective leadership and collective empowerment.

Dialogue or collective thinking helps communities and their leaders create a climate that can lead to greater collaboration, fluidity, collective and inclusive learning, and sustainability (Kirk \& Shutte 2004) of DRR activities. Kirk and Shutte (2004) further contend that dialogue can lead to agreements even if community members may not agree to the direction to be followed. They further state the conditions under which dialogue can yield positive results. In the context of DRR, community members should feel good enough, safe enough and the environment should be open enough to identify and map hazards, express their vulnerability and capacity, and deal with uncertainties and difficulties in order to construct appropriate responses to the realities obtaining in their community. In this way, DRR leadership could be viewed as a collective distributed phenomenon that is constructed around dialogue as a means to enhancing resilience to disasters.

Connective leadership also integrates the gendered notions of leadership (Kirk \& Shuttle 2004). Kirk and Shutte (2004) further state three concerns of connective leadership. Firstly, it helps individuals integrate their desires with community or organisational goals. In the context of DRR, an individual identifies DRR goals, takes ownership of the goals and chooses actions to achieve the goals. Secondly, connective leadership encourages members to collectively explore the possibilities and potential of connecting with a common goal. In relation to DRR, this might include team work before and after a disaster, particularly in community projects. Finally, connective leadership helps create and sustain a creative space where collective leadership can flourish. The DRR leadership will foster collaboration and enable different voices to be heard, including those of vulnerable groups such as children, women and the elderly and disabled persons. The leadership will not necessarily come from just one direction but from multiple directions.

Kirk and Shutte (2004) also state that collective empowerment helps individuals to find their place, their role, their identity and their voice in the system. As individuals become interconnected in all parts of the system and have a clear conception of their roles, they develop fruitful relationships with others, clarity about purpose, meaning and value in their work. Consequently, individuals then take responsibility for themselves in relationship to others, their work, the system they are in and the larger environment that contains their system. Kirk and Shutte's (2004) framework promotes partnership between individuals and groups who essentially need to work together to build resilient communities where the values of empowerment, inclusivity, accountability, collaboration and transparency are paramount. 


\section{DISCUSSION OF THE FINDINGS:}

Based on interviews of all respondents, they said that in the initial stages of disaster response, affected people are always concerned, whether the leader, understood and interpreted the scope of the disaster correctly and how will they be led out of it. This calls for a leader who has insightful skill that give them the rich and profound understanding of the complex challenges that they are about to face and deal with. In addition, most of the respondents noted that leaders should have skill to effectively respond in the aftermath of a disaster. It is the necessary competencies that a leader needs to have to be able to accomplish the task of leading a disaster response phase effectively. Leaders must have skill of insight are able to overcome the challenges by taking responsibility for building a common understanding, motivation, inspiration, trust and hope for victims and all the populations that were affected by the disaster.

Most of the studied people agreed that building a common understanding in this case, must be started with the leaders delineating the scope of the disaster to all stakeholders, giving details of what has emerged in the disaster based on an informed knowledge, sources and experience. This is seen as an important first step in creating awareness to the public and taking of control of the response phase by the leader.

This study revealed that the ability of a leader, who runs a disaster response, to agree with the onset of a disaster, understanding the causes or vulnerabilities, challenges and opportunities, is essential for an effective response. It is by examining and interpreting the scope of the disaster, in the first case for themselves and then for the victims. In addition, all respondents said that constructing an understanding of the prevailing situation and taking control of the disaster response phase is a key first step for leaders in effectively managing disaster response. Leaders must be insightful in responding to disasters are able to actively evaluate the response capacity that needs to be deployed in terms of resources. Nevertheless, this can be an intimidating challenge.

All the interviewed people thought that in the event of a disaster, the challenge for leaders and those on the disaster response team is the ability to have a mutual understanding and apprehending of the scope, magnitude, characteristics and consequences of the disaster. This has been proven to be a hurdle for leaders who respond to disasters.

It is found from the study that decision making in responding disaster is crucial, complicated, sensible and competent that affects the lives of many in disaster response phase, relying only on limited information and quick evaluation, as the core of disaster response leadership and the benchmark by which leaders actions are to be judged. Most of the respondents noted that the leaders must have a responsibility to make decisions on all aspects and benchmarks of the response phase, it is on behalf of victims who are in distress and do not have the power to decide for themselves. In addition, they noted that leaders must be able to prioritize their decision-making process based on needs and resources and be able to focus on their consequences. Leaders who respond to disasters must be able to make decisions about the deployment and management of the response plan because the response phase is confusing and interrupted and requires urgent and quick actions to save lives and property.

On the other hand, some respondents argued that not only decision making, quality decision making is a major challenge while responding to disaster. Those responsible for disaster response have a responsibility to make quality decisions and to be able to respect them, as they define the future of all the actors involved in the whole operation. All respondents noted that in order to achieve an effective and successful response, leaders need to be flexible in adapting to changing events and making changes in their decision for the benefit of all stakeholders and processes.

It found from the study that responding to disasters requires adequate networking and collaboration that are essential to generate the resources needed to respond. When leaders respond to disasters, they interact with different teams, authorities and organizations with which they have never worked before. These organizations or units usually have different roles and systems of operations. Therefore, leaders must have networking skills to overcome this barrier. Leaders with networking skills must use their personal influence and dynamism to involve all stakeholders and authorities at the local community level, involving the first responding organizations such as police, ambulances and the national and international arena.

It revealed that leaders must use the networking skills to build respect, trust and relationships at all levels of response to local and national disasters. This is essential for the establishment of a working platform that will reduce conflict and create a conflict resolution mechanism that can promote collaboration and networking. All people of this study believe that leaders must use the effective networking skills foe adapting quickly against the changing environment. They can do this by building teams and bridges, entrusting operations and powers to others, instead of centralizing command and decision-making. The technology has been used by disaster-makers to facilitate the networking process, including telecommunication networks, Internet interfaces and others. All the respondents strongly believed that the success of disaster leadership is directly related to the interactions and partnerships they create and sustain throughout the process. These networks are essential to develop a common approach in dealing with challenges in the response phase.

Most of the studied people thought that leaders mush have effective communication skills, have the ability to be open, they must able to listen from all sides and are able to learn from the challenges encountered. They must be willing to share information without discrimination and to express their views without fear. The prime challenge for leaders in the response phase is the communication failure or overload. Leaders who respond to disasters have the challenge of verifying information in the dynamic and evolving context that they operate around. Leaders must therefore have critical communication skills that involve active listening and comprehending that they gasp the scope of information relayed and are able to relay it efficiently and relevantly.

All respondents said that effective leaders with good communication skills must develop modalities to increase information sharing through appropriate communication by taking advantage of the various communication technologies and channels available to remove barriers. Thus, leaders having good communication skills should strive to achieve the effective means available when the communication systems in the disaster response plan fail to work. The studied people noted that an effective contingency plan must always anticipate failures in communication systems that may hamper response efforts. Disaster preparedness plans should be able to clearly indicate how the challenges associated with communication 
disasters will be addressed.

It is noted from this study that leaders must accountable during responding time; leaders must be accountable for how they exercise their power to make decisions and relocate resources. A leader must be accountable to build trust and respect with all the stakeholders involved. It is seen in many quarters as being able to show that a leader recognizes his moral and legal obligations, but this is not always the case.

It noted from this study that accountable leaders are able to employ means and systems that will enhance transparency in relief and rescue activities, ensuring that all resources are appropriately used and accounted for effective leadership. Systems should therefore be put in place to obtain feedback from the affected populations and the modalities for resolving the conflicts amicably, made operational.

All the studied people noted that leaders must have keen interest to learn are able to recognize their mistakes and learn from them and accumulate experience to ensure that the disaster response phase continues to develop on the basis of best practices and better policies and approaches. It is important to note, however, that no two type of disaster can have similar experiences, but there are generally lessons to be learned and shared among the leaders. All respondents of this study believed that an effective leader in disaster response is one who learns to take a keen interest in the loopholes created by factors such as policy and regulations, cultures and systems that have greater bearing to the activities and function of rescue and relief efforts. These leaders are ready to challenge the status quo and initiate the change processes needed in the rescue and relief field.

\section{CONCLUSION:}

This study demonstrated the importance of leadership competence, for leaders who respond to the disasters. The success of the disaster response phase is largely linked to the fact that leaders have the right skills and put them into practice when necessary. However, as the dynamics of disaster leadership continues to change, emphasis will shift from leadership skills to organizational structures and cultures that affects to a greater extent, the bearing and quality of leadership performance in disaster response phase. The findings of this study should be considered by policy makers and relevant stakeholders of Bangladesh so that relevant training on leadership on disaster management would be provided to respective people for ensuring effective and efficient response as Bangladesh is one of the most vulnerable countries due to disasters. This study also explores gaps in disaster-leadership research and scholarship, which apparently has been implied under the disaster management and governance rubric. Finally, whilst the findings of this study may be specific to the Bangladesh context, they may resonate with similar contexts elsewhere.

\section{REFERENCES}

1. Akter, S., Mallick, B. (2016). The poverty-vulnerabilityresilience nexus: Evidence from Bangladesh. Ecological Economics 96: 114-124.

2. Anderson, D. (2002). Leading in crisis. Executive Excellence, 19(8), 4.

3. Asgary, A., and Halim, A. (2011). Measuring people's preferences for cyclone vulnerability reduction measures in Bangladesh. Disaster Prevention and Management, 20 (2), 186-198.
4. Bass, B.M., 1985, Leadership and performance beyond expectations, Free Press, New York.

5. Buck, D.A., Trainor, J.E. \& Aguirre, B.E., 2006, 'A critical evaluation of the incident command system and NIMS', Journal of Homeland Security and Emergency Management 3(3), 1-27. http://dx.doi.org/10.2202/15477355.1252

6. Carvalho, J.B.L., 2015, 'Building local level engagement in disaster risk reduction: A Portuguese case study', Disaster Prevention and Management: An International Journal 24(1), 80-99. http://dx.doi.org/10.1108/DPM-07-2014$\underline{0129}$

7. de Bussy, N.M. \& Paterson, A., 2012, 'Crisis leadership styles-Bligh versus Gillard: A content analysis of Twitter posts on the Queensland floods', Journal of Public Affairs 12(4), 326-332. http://dx.doi.org/10.1002/pa.1428

8. Drath, W. \& Palus, C., 1994, Making common sense: Leadership as meaning-making in communities of practice, Center for Creative Leadership, Greensboro.

9. Dynes, R.R., 1994, 'Community emergency planning: False assumptions and Inappropriate analogies', International Journal of Mass Emergencies and Disasters 12(2), 141-158.

10. Fielder, F.E., 1967, A theory of leadership effectiveness, McGraw-Hill, New York.

11. Hailey, J., 2006, Praxis Paper 10, NGO leadership, development: A review of the literature, INTRAC, viewed n.d., $\quad$ from http://www.dochas.ie/Shared/Files/2/INTRAC_Praxis_Paper_10_ NGO_Leadership.pdf

12. Hannah, S. T., Uhl-Bien, M., Avolio, B. J., Cavarretta, F. L. (2009). A framework for examining leadership in extreme contexts. The Leadership Quarterly, 20(6), 897919.

13. Horner, M., 1997, 'Leadership theory: Past, present and future', Team Performance Management: An International Journal 3(4), 270-287. http://dx.doi.org/10.1108/13527599710195402

14. Karim, A., \& Noy, I. (2015). Poverty and Natural Disasters-A Qualitative Survey of the Empirical Literature. The Singapore Economic Review (forthcoming), Published online DOI: $10.1142 / \mathrm{S} 0217590816400014$

15. Kirk, P. \& Shutte, A.M., 2004, 'Community leadership development', Community Development Journal 39(3), 234-251. http://dx.doi.org/10.1093/cdj/bsh019

16. Kouzes, J.M. \& Posner, B.Z., 1995, The leadership challenge, 4th edn., John Wiley \& Sons, Willowbrook.

17. Perry, R.W., 2003, 'Incident management systems in disaster management', Disaster Prevention and Management: An International Journal 12(5), 405-412.

18. Stogdill, R.M., 1950, 'Leadership, membership and organization', Psychological Bulletin 47, 1-14. http://dx.doi.org/10.1037/h0053857

19. Tasneem, S. \& Shindaini, A.J.M. (2013). The Effects of Climate Change on Agriculture and Poverty in Coastal Bangladesh. Journal of Environment and Earth Science, 3(10), 186-192.

20. Yunus, N.H.P. \& Anuar, S.R., 2012, 'Trust as moderating effect between emotional intelligence and transformational leadership styles', Interdisciplinary Journal of Contemporary Research in Business 3(10), 650-663.

21. Zolli, A. \& Healy, A.M., 2012, Resilience: Why things bounce back, Headline, London. 